\title{
Germline truncating mutations in both MSH2 and BRCA2 in a single kindred
}

\author{
I Thiffault ${ }^{1,3,4}$, N Hamel',4, T Pal', S McVety',3, VA Marcus², D Farber ${ }^{1,2}$, S Cowie ${ }^{6}$, J Deschênes²,

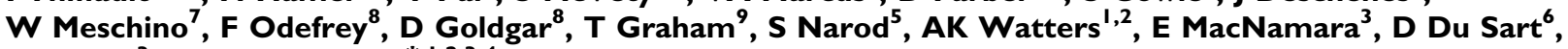 \\ G Chong ${ }^{3}$ and WD Foulkes ${ }^{*, 1,2,3,4}$
}

'Program in Cancer Genetics, Department of Oncology and Human Genetics, McGill University, Montreal, Quebec, Canada; ${ }^{2}$ Department of Pathology, McGill University, Montreal, Quebec, Canada; ${ }^{3}$ Department of Diagnostic Medicine, SMBD-Jewish General Hospital; ${ }^{4}$ Research Institute of the McGill University Health Centre, Montreal, Quebec, Canada; ${ }^{5}$ Centre for Research in Woman's Health, University of Toronto, Toronto, Ontario, Canada; ${ }^{6}$ Murdoch Children's Research Institute, Melbourne, Australia; ${ }^{7}$ Department of Genetics, North York General Hospital, University of Toronto, Toronto, Ontario, Canada; ${ }^{8}$ IARC, Lyon, France; ${ }^{9}$ Preventive Oncology Program, Toronto Sunnybrook Regional Cancer Centre, Toronto, Ontario, Canada

\begin{abstract}
There has been interest in the literature in the possible existence of a gene that predisposes to both breast cancer (BC) and colorectal cancer (CRC). We describe the detailed characterisation of one kindred, MONI080, with 10 cases of BC or CRC invasive cancer among 26 first-, second- or third-degree relatives. Linkage analysis suggested that a mutation was present in BRCA2. DNA sequencing from III: 22 (diagnosed with lobular BC) identified a BRCA2 exon 3 542G > T (LI 05X) mutation. Her sister (III: 25) had BC and endometrial cancer and carries the same mutation. Following immunohistochemical and microsatellite instability studies, mutation analysis by protein truncation test, cDNA sequencing and quantitative real-time PCR revealed a deletion of MSH2 exon 8 in III: 25 , confirming her as a double heterozygote for truncating mutations in both BRCA2 and MSH2. The exon 8 deletion was identified as a $14.9 \mathrm{~kb}$ deletion occurring between two Alu sequences. The breakpoint lies within a sequence of $45 \mathrm{bp}$ that is identical in both Alu sequences. In this large BC/CRC kindred, MONI080, disease-causing truncating mutations are present in both MSH2 and BRCA2. There appeared to be no increased susceptibility to the development of colorectal tumours in BRCA2 mutation carriers or to the development of breast tumours in MSH2 mutation carriers. Additionally, two double heterozygotes did not appear to have a different phenotype than would be expected from the presence of a mutation in each gene alone.
\end{abstract}

British Journal of Cancer (2004) 90,483-49I. doi:I0.1038/sj.bjc.660I424 www.bjcancer.com

(c) 2004 Cancer Research UK

Keywords: MSH2; BRCA2; microsatellite instability; colorectal cancer; breast cancer; astrocytoma; multiple primary cancers

$B R C A 1$ and $B R C A 2$ are the most important susceptibility genes for breast and ovarian cancer, and mutations in these two genes account for $>80 \%$ of all kindreds with hereditary breast/ovarian cancer and for about $2-3 \%$ of breast cancer (BC) cases overall. Hereditary nonpolyposis colorectal cancer (HNPCC) is the most common form of hereditary colorectal cancer (CRC) (Lynch and de la Chapelle, 1999) and is responsible for $0.5-3 \%$ of all cases of CRC. Mutations in the DNA repair genes $M L H 1$ and $M S H 2$ segregate in up to $90 \%$ of HNPCC pedigrees (Peltomaki, 2001).

Several groups have studied the genetic relationship between breast and colorectal cancer, with varying findings. In one large Dutch family with a segregating BRCA1 mutation, there are several mutation carriers who have developed CRC. However, detailed analysis suggested that the BRCA1 mutation was not contributing to the CRCs observed. By contrast, in a large international study, Thompson et al (2002) observed a relative risk of $2.03(P<0.001)$

* Correspondence: Dr WD Foulkes, Montreal General Hospital, Room LI0-120, 1650 Cedar Avenue, Montreal, Quebec, Canada H3G IA4; E-mail: William.foulkes@mcgill.ca

Received 24 March 2003; revised 14 August 2003; accepted 20 September 2003 for CRC in BRCA1 mutation carriers, compared with general population cancer incidence. Studies in HNPCC kindreds have shown no excess of $\mathrm{BC}$, or have shown that when $\mathrm{BC}$ does occur, microsatellite instability (MSI), a hallmark of HNPCC-related cancer, is usually absent (Aarnio et al, 1995; Caluseriu et al, 2001). Interestingly, Borg et al reported a family with two missense mutations in MLH1 and a single truncating mutation in BRCA1. The double heterozygote for the missense $M L H 1$ and truncating $B R C A 1$ mutations developed BC but not colorectal or endometrial cancer. The authors proposed a possible protective effect of BRCAI deficiency against carcinogenic event in the colon (Borg et al, 2000).

In general, studies of female BC in HNPCC families have found little evidence for MSI (Muller et al, 2002), but Boyd and colleagues did find a role for MMR genes in $\mathrm{BC}$ susceptibility by performing molecular genetics studies in five patients with BC from HNPCC families. Microsatellite instability was observed in three of the five tumours. In one family member with a 4-bp frame-shift mutation in $M L H 1$, expression of only the mutant allele was observed in the BC tissue (Risinger et al, 1996).

It is not uncommon to see pedigrees with several cases of $\mathrm{BC}$ and CRC. Given this clinical observation, and the data presented above, the question of whether a single gene that predisposes to 
both BC and CRC exists is pertinent. Here, we describe the investigation of one of the most convincing $\mathrm{BC} / \mathrm{CRC}$ pedigrees reported. MON1080 is a 26-member kindred that includes five cases of CRC and five cases of BC (Figure 1). The family meets Amsterdam criteria I for the diagnosis of HNPCC (Vasen et al, 1999), and nine of the 10 cases of cancer were diagnosed under the age of 45 years.

\section{PATIENTS AND METHODS}

\section{Patients}

A detailed family history was taken from a total of 26 related individuals from kindred MON1080. There were 17 female and nine male subjects. The details are shown in Figure 1, and all cancers were histopathologically confirmed, unless otherwise indicated.

\section{Immunohistochemistry (IHC) analysis}

Immunohistochemistry for MLH1 and MSH2 proteins was performed as a screening test for DNA mismatch repair-deficient tumours. Mouse monoclonal antibodies G168-728 (MLH1, BD Pharmingen, San Diego, CA, USA) and FE11 ( $M S H 2$, Oncogene Research Products, San Diego, CA, USA) were used (Marcus et al, 1999). Surrounding normal mucosa and lymphocytes served as internal positive controls. MLH1 and MSH2 IHC was performed on the villoglandular polyp and the endometrioid adenocarcinoma of the uterus from patient III: 25; on the anal carcinoma and keratoacanthoma of patient III: 10; and on the astrocytoma of patient II: 11. Immunohistochemistry was also performed on the available BC from patients III: 5, III: 18, III: 17, III: 22 and III: 25 for ER (clone 6F11, Ventana, Tucson, AZ, USA), PR (clone 16, Zymed, San Francisco, CA, USA), CDH-1 (clone 4A2 C7, Zymed, San Francisco, CA, USA), MIB-1 (clone MMI, Novocastra, Newcastel, UK), P53 (clone DO-7, Dako, Denmark) and HER2 (clone Tab 250, Zymed, San Francisco, CA, USA) proteins.

\section{Microsatellite instability analysis}

Microsatellite instability analysis was performed on microdissected tissues using five MSI markers: BAT25, BAT26, D2S123, D5S346 and D17S250. According to international criteria, MSI is defined as high-degree instability (MSI-H) if there is instability at two out of five loci (Boland et al, 1998). Microsatellite instability was performed on DNA extracted from the villoglandular polyp and the endometrial cancer of patient III: 25, on the anal carcinoma and keratoacanthoma of patient III: 10 and on the astrocytoma of patient II: 11. Following extraction of DNA from paraffinembedded tissue, PCRs were performed using primer pairs, one of which was fluorescently labelled with Cy5.5. The products were visualised by fragment size analysis on an OpenGene System (Visible Genetics, Ontario, Canada). Anal carcinoma is not a common tumour in HNPCC kindreds, but we tested the anal and skin tumour of patient III: 10 because skin tumours are a feature of the HNPCC variant, Muir-Torre syndrome (MTS) and keratoacanthoma with MSI-H and loss of expression of MMR genes (MSH2 or MLH1) have been reported to occur in MTS (Honchel et al, 1994; Kruse et al, 1996; Entius et al, 2000).

\section{DNA and RNA extraction and RT-PCR}

Peripheral blood lymphocytes were separated from $16 \mathrm{ml}$ of whole blood using the Accuspin ${ }^{\mathrm{TM}}$ System-Histopaque ${ }^{\mathrm{R}}-1077$ from Sigma Diagnostics (St Louis, MO, USA). Total RNA was extracted using Trizol Reagent (Invitrogen Canada, Burlington, Ontario, Canada). DNA was extracted with the PUREGENE ${ }^{\mathbb{R}}$ Genomic DNA Isolation Kit from Gentra Systems (Minneapolis, MN, USA). Oligo(dT)primed cDNAs were synthesised using the SuperScript ${ }^{\mathrm{TM}}$ Preamplification System for First Strand cDNA Synthesis kit (Invitrogen). The complete open reading frame of $M S H 2$ was then amplified as two overlapping segments from $2 \mu \mathrm{l}$ of the cDNA reaction using primers previously described by Luce et al (1995).

\section{Protein truncation test (PTT) and sequence analysis of MSH2 cDNA}

We used the $\mathrm{TNT}^{\circledR}$ Quick-Coupled Transcription/Translation kit from Promega (Madison, WI, USA) for PTT. The PCR-amplified cDNA segments were transcribed and translated in vitro in a reaction mixture containing ${ }^{35} \mathrm{~S}$-labelled methionine, and the resultant polypeptides were separated on a $12 \%$ polyacrylamide SDS gel, dried and subjected to autoradiography. Sequencing was carried out on PCR-amplified cDNA segments by cycle sequencing using Thermo Sequenase enzyme. PCR products were separated by electrophoresis on low-melt agarose gel. The fragments were

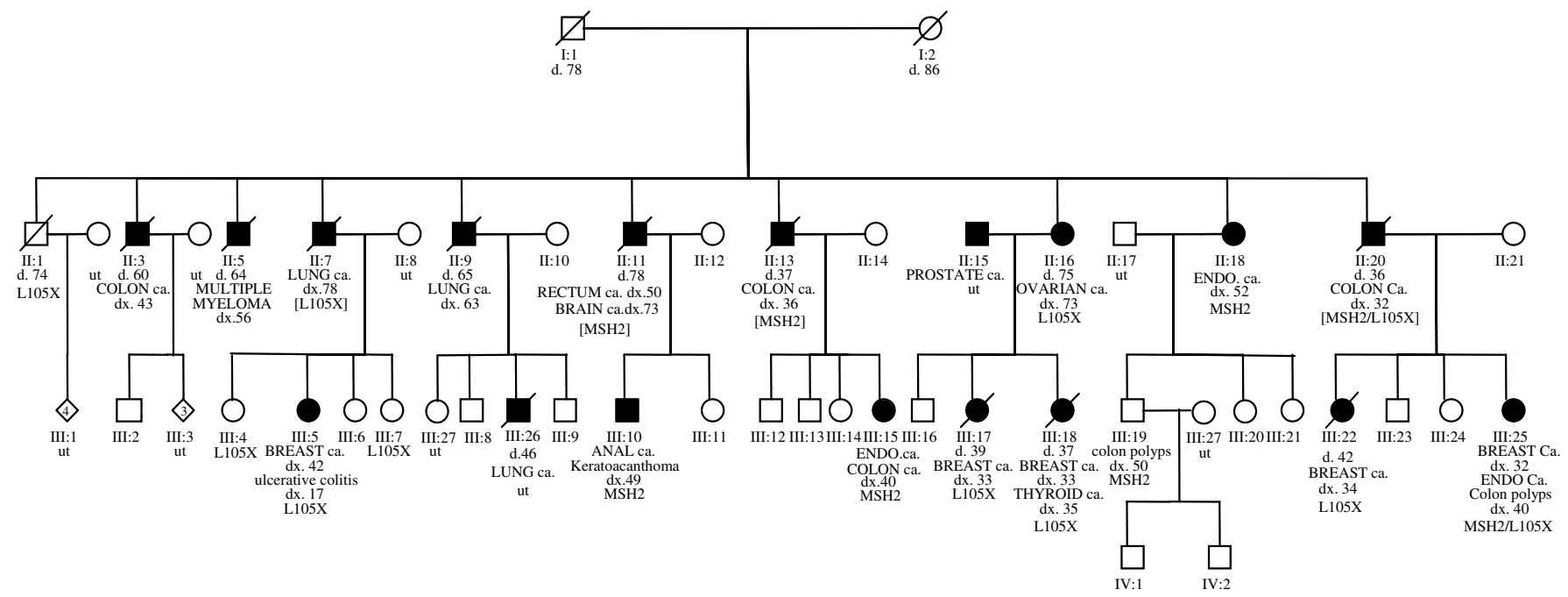

Figure I Hereditary breast and CRC Family MONI080. The numbers immediately under the symbols are individual numbers. The abbreviation 'ut' indicates untested. Mutations in brackets are inferred. $M S H 2=M S H 2$ exon 8 deletion present. LI05X $=B R C A 2 * L 105 X$ mutation present. $\mathrm{ENDO}=$ endometrial cancer. 
excised from the gel and purified using the QIAquick Gel Extraction kit (QIAGEN, Mississauga, Ontario, Canada). The purified fragments were then sequenced using the Thermo Sequenase Cy5.5 Dye Terminator Sequencing Kit from Pharmacia (Uppsala, Sweden).

\section{MSH2 mutation analysis by real-time PCR}

The real-time PCR was carried out as a duplex PCR amplifying exon $8 \mathrm{MSH} 2$ and CFTR exon 24 as an internal control in a reaction volume of $25 \mu \mathrm{l}$ using the Brilliant QPCR kit (Stratagene, Integrated Sciences, East Kew Victoria, Australia). TaqMan fluorescent probes were synthesised according to the Applied Biosystems primer express software program, allowing standard amplification thermal cycling conditions (denaturation $95^{\circ} \mathrm{C}$ for $10 \mathrm{~min}$, and subsequent cycles of $95^{\circ} \mathrm{C}$ for $15 \mathrm{~s}$ and $60^{\circ} \mathrm{C}$ for $1 \mathrm{~min}$ for 40 cycles). The PCR reaction mixture consisted of $200 \mathrm{~nm}$ each of MSH2 exon 8-specific forward 5'-AGAAATTATTGTTGGCAGTTTTTGTG- $3^{\prime}$ and reverse $5^{\prime}$-CATATCTAAAGTTGTTTCTATCATTTCCTG- $3^{\prime}$ primers and the CFTR forward $5^{\prime}$ GAAGAGAACAAAGTGCGGCAG- $3^{\prime}$ and reverse $5^{\prime}$-TTGCCGGAAGAGGCTCCT- $3^{\prime}$ primers, $100 \mathrm{~nm}$ FAM-labelled MSH2 exon 8-specific probe (6FAM-CTCCTCTTACTGATCTTCGTTCTGACTTCTCCAAG) and $400 \mathrm{~nm}$ Hex-labelled CFTR exon 24 probe (HEX-ACGATTCCATCCAGAAACTGCTGAACGA), to a final concentration of $5.0 \mathrm{~mm} \mathrm{MgCl}_{2}$ and $200 \mathrm{ng}$ DNA sample. Amplifications were carried out in the iCycler detection system (Biorad, Regents Park, NSW, Australia) and analyses were performed in triplicate.

\section{MSH2 genomic DNA sequencing}

The region containing the deletion was first amplified from genomic DNA by long-range PCR using the Expand LT and Expand $20 \mathrm{~Kb}^{\mathrm{PLUS}}$ PCR Systems (Roche, Indianapolis, IN, USA) and the following primers: MSH2 IVS7-5K-F Tm 68 (5'-ACTTCTTACTCCTTACTTCCTACTT- $\left.3^{\prime}\right)$, MSH2 IVS8-10K-R Tm 68 (5'AACAGGAGAGACCGCTAATAGATA-3'), TAAA-Rpt (5'-TGAGTATTGCTCTCTTGCTATCTTG- $\left.3^{\prime}\right)$, and H2 EX8 ALUYF $\left(5^{\prime}-\right.$ AACTTTGCCACCCATTTCAG- $3^{\prime}$ ). The deletion region was also amplified using Platinum Taq (Invitrogen), the PCR Core Kit (Qiagen), and the following primers: H2 EX8 ALUYF (5'AACTTTGCCACCCATTTCAG- $\left.3^{\prime}\right)$ and MSH2, IVS8 10318R ( $5^{\prime}$ TTTGCTTGCTGATGTTCTGG- ${ }^{\prime}$ ). The reaction mixture was prepared according to the manufacturer's protocol. The following thermocycling conditions were used: denaturation $95^{\circ} \mathrm{C}$ for $2 \mathrm{~min}$, and 35 cycles of $95^{\circ} \mathrm{C}$ for $10 \mathrm{~s}, 60^{\circ} \mathrm{C}$ for $30 \mathrm{~s}$ and $68^{\circ} \mathrm{C}$ for $20-$ $30 \mathrm{~min}$, depending on the expected size of the wild-type product. The PCR products that contained the expected deletion were cut from the agarose gel, purified by QIAquick PCR purification Kit (Quiagen, Chatsworth, CA, USA) and sequenced using the same primers and the Thermo Sequenase Cy 5.5 Terminator Cycle Sequencing Kit (Pharmacia) according to the manufacturer's instructions.

\section{$B R C A 2$ mutation analysis}

DNA from individual III: 22 was sent to Myriad Genetics Laboratories for a complete sequencing analysis of $B R C A 1$ and $B R C A 2$. Following this, we used direct sequencing for individuals III: 22 and III: 25 . Other family members were subsequently tested by single-strand conformation analysis (SSCA) using primers flanking the mutation: F-5'-CCGCTGTACCAATCTCCTGT- $3^{\prime}$ and R-5'-GAGACTGATTTGCCCAGCAT-3'. PCR products were amplified using the Taq Gold amplification system (Perkin-Elmer) in the presence of $\left[{ }^{35} \mathrm{~S}\right] \mathrm{dATP}$ at $95^{\circ} \mathrm{C}(30 \mathrm{~s}), 60^{\circ} \mathrm{C}(30 \mathrm{~s}), 72^{\circ} \mathrm{C}(30 \mathrm{~s})$ for 35 cycles, then separated on a $0.5 \times \mathrm{MDE}$ gel for $6 \mathrm{~h} 30 \mathrm{~min}(25 \mathrm{~W}$, $4^{\circ} \mathrm{C}$ ). The presence of an additional band was evidence for the presence of the mutation.

\section{Haplotype analysis}

Haplotype analysis was performed on each individual using singlenucleotide polymorphisms (SNPs) and microsatellites within or near BRCA2 or MSH2. Two tetranucleotide repeat microsatellites (TTTA: intron 2; TAAA: intron 7) within MSH2 on chromosome 2 (Desai et al, 2000) were visualised by fragment size analysis on an OpenGene System (Visible Genetics, Ontario, Canada). Five polymorphic markers within or near BRCA2 (D13S1694, D13S1695, D13S1697, D13S260 and D13S1698) were used to distinguish between the chromosomes segregating in the family (Table 1). Primer sequences and PCR amplification conditions can be found in the Genome Database (GDB, http://gdbwww.gdb.org/ $\mathrm{gdb} /$ ). PCR products were separated on denaturing acrylamide gels and visualised by autoradiography.

\section{RESULTS}

\section{Immunohistochemistry analysis}

Several pathology samples from patient III: 25 were evaluated by IHC. A moderately well differentiated, endometrioid adenocarcinoma of the uterus showed weak nuclear staining of the carcinoma with both antibodies. The second sample was a small villotubular adenoma that showed strong nuclear staining with the MLH1 antibody, whereas no staining with the MSH2 antibody was observed in the adenoma. Thus, there was no evidence of mismatch repair-deficiency from inactivation of MLH1 in either of these two samples, but the findings suggested $\mathrm{MSH} 2$ inactivation in the colonic adenoma. Immunohistochemistry for MLH1 and MSH2 was also performed on the anal squamous cell carcinoma and keratoacanthoma from patient III: 10. Both lesions displayed nuclear staining with the two antibodies, showing no evidence of MLH1 or MSH2 inactivation in these samples. The results for the brain tumour from II: 11 suggested inactivation of MSH2 (Figure 2), as shown by the lack of staining in the astrocytoma, whereas IHC staining with the MLH1 antibody was normal. Immunohistochemistry analysis of the available BCs is shown in Table 2. In particular, III: 25, discussed above, developed an invasive BC, which was ER/PR positive. None of the four breast tumours analysed overexpressed HER2. Loss of E-cadherin expression was noted in two breast cancers, whereas in one case it was overabundant.

\section{MSI analysis}

Of the five samples subjected to MSI analysis, one (III: 25; DNA from a villotubular adenoma) showed high degree of instability at three out of five loci (BAT25, BAT26, D5S346), and the endometrioid adenocarcinoma of the uterus was MSI-L (only BAT-25 was unstable). Interestingly, patient II: 11, from whom brain tumour tissue was available, showed MSI for BAT-25 and D2S123; the other loci were stable (Figure 2). The keratoacanthoma and the anal carcinoma from patient III: 10 were microsatellite stable (MSS).

\section{MSH2 mutation analysis}

A truncated protein in the $\mathrm{MSH} 2$ gene was identified by PTT in one woman (III: 25) who had a colon polyp and endometrial cancer. To precisely locate the underlying cause of the truncation, we used cDNA to amplify a segment spanning exons 5-9. Electrophoretic separation of the PCR products showed the presence of an additional smaller fragment. Sequencing of this fragment revealed a deletion of exon 8 from the cDNA 
Table I Mutation and haplotype results in family MONI080

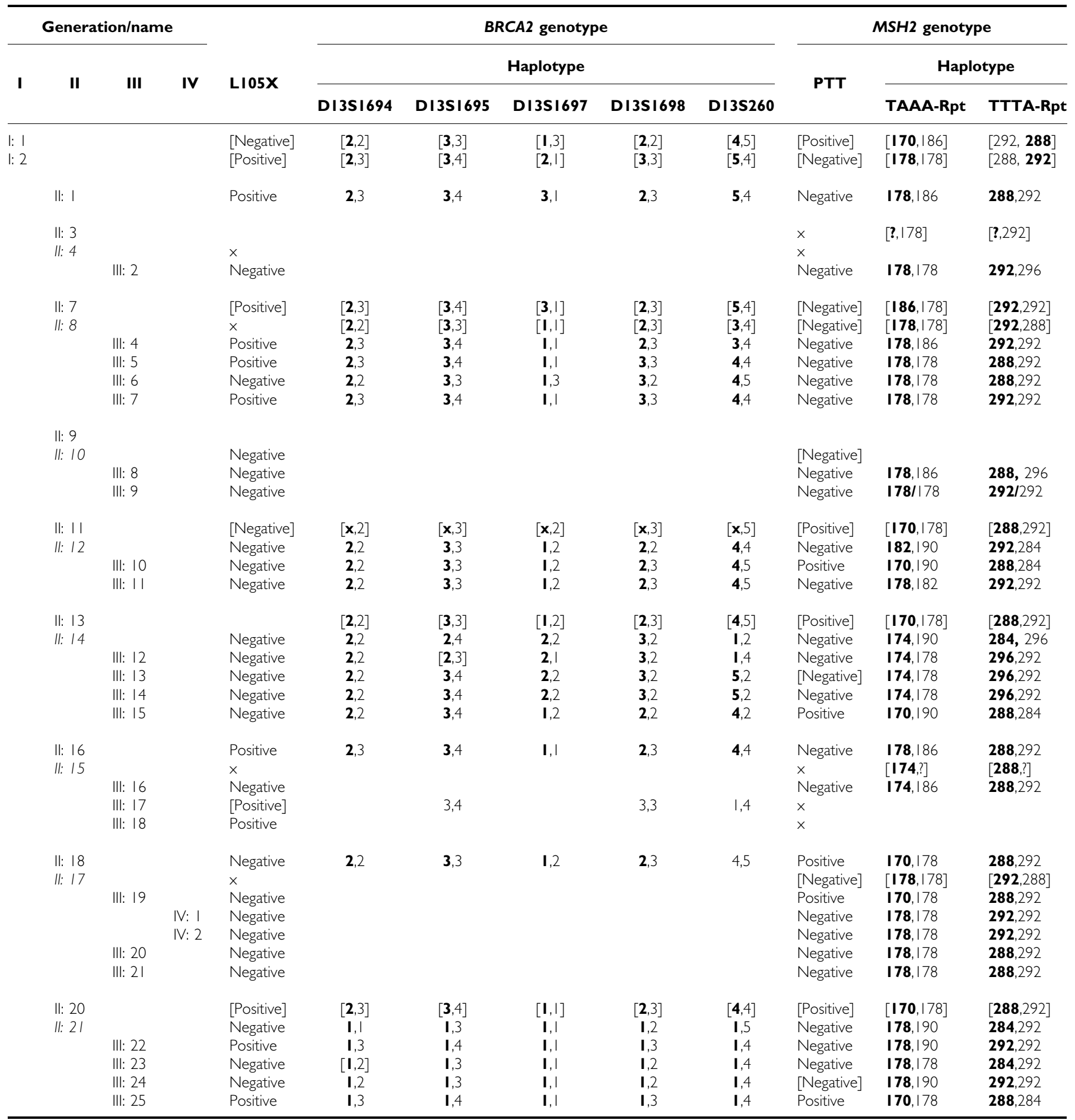

Italic: married to MONI080 family member. Bold number: distinguish the phase of the hapotypes. [Brackets and grey text]: result inferred (not from direct testing. II: I0 -PTT not done, status determined by real-time PCR). Since all results regarding the parents are inferred, the BRCA2 mutation was assigned arbitrarily to one individual from generation I. Linked haplotype: BRCA2: 3, 4, I, 3, 4 MSH2: 170, 288.

segment (Figure 2). The deletion is out of frame, and results in a stop codon 12 nucleotides downstream of exon 9 (at nucleotide 1398). DNA sequencing of the exon 8 and the flanking intronic regions did not reveal any alteration of the consensus splice sites, indicating that the exon 8 deletion was most likely caused by a large genomic deletion of the region encompassing exon 8.
In the quantitative real-time PCR analysis, normalised values for nondeleted patients and normal controls are equal to one; the normalised values for positive controls and deleted patients are equal to zero. Real-time PCR analysis confirmed the presence of a germline intragenic deletion encompassing exon 8 and flanking intronic sequences in the patients showing a truncation in $\mathrm{MSH} 2$ by PTT (Table 1). DNA from II: 20 was not available for testing, 
A

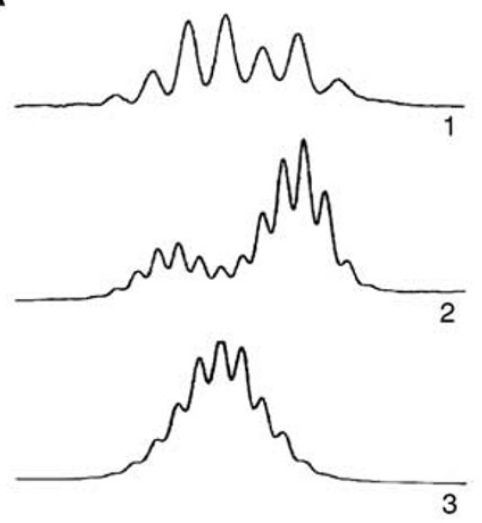

C

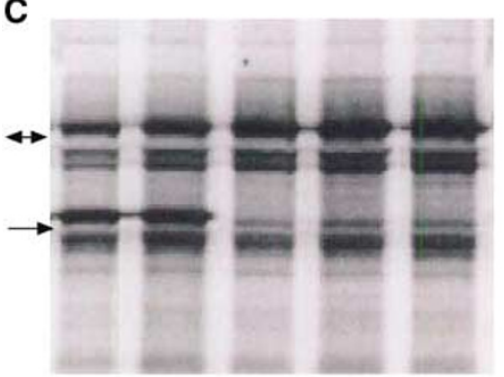

E

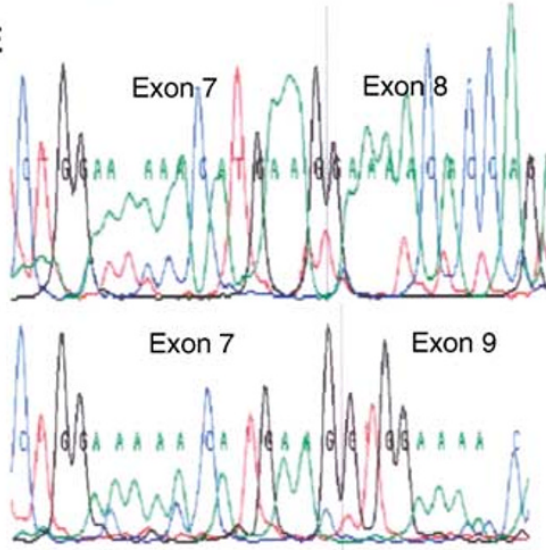

B

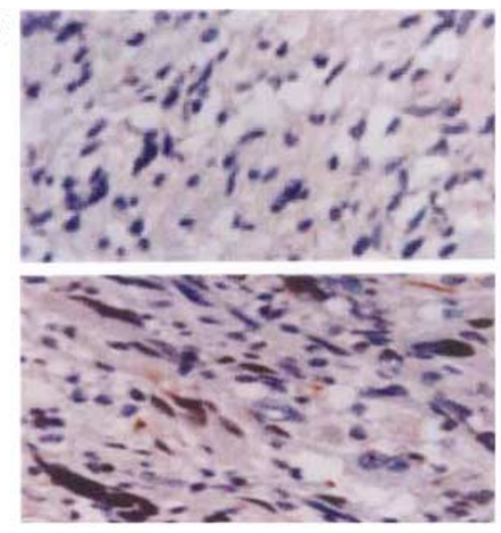

D

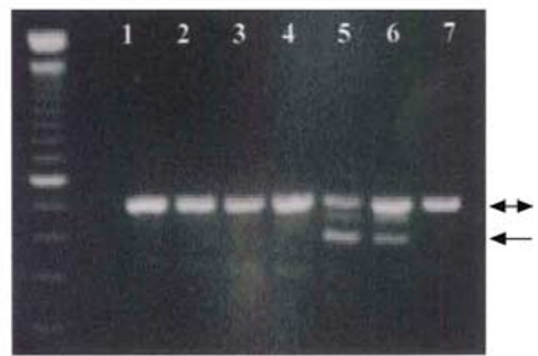

Figure 2 (A) Microsatellite instability at various loci in astrocytoma of patient II: 20. (I) D2S I 23; (2) BAT 25 and (3) BAT 26. (B) Immunohistochemical staining for MSH2 and MLHI in the astrocytoma of patient II: 20. Upper panel: lack of staining for the MSH2 antibody indicating MSH2 inactivation in the tumour. Lower panel: normal staining of MLHI in the astrocytoma $(\times 400)$. (C) Protein truncation test shows a truncated protein in patients II: I 8 and III: 25. (Lanes I and 2) the double-headed arrow indicates the protein product from the normal allele. The single arrow indicates the truncated protein. (D) PCR products of CDNA segment including exons 5-9. Lanes I-7: the double headed arrrow indicates PCR product of normal allele. Lanes 5 and 6: single arrow indicates PCR product of mutant allele. (E) The first sequence of cDNA shows the junction of exons 7 and 8 . The second sequence shows the exon 8 deletion found in patients with HNPCC-related cancers in family MONI080.

but the absence of the mutation in his widow's (data not shown) cDNA (II: 21) (as well as haplotype analysis, see below) were sufficient to confirm that II: 20, who died of CRC at 36 years of age, was an obligate carrier.

\section{MSH2 genomic DNA sequencing}

Long-range PCR on genomic DNA was used to confirm the deletion and to locate the region containing the breakpoint. Different sets of primers were used to exactly characterise the deletion at the junction site. A $1.9 \mathrm{~kb}$ fragment containing the deletion breakpoint was then amplified from genomic DNA with the following primers: H2 EX8 ALUYF and MSH2, IVS8 10318R.
The exon 8 deletion was identified as a $14.9 \mathrm{~kb}$ deletion occurring between two Alu sequences. The localisation of the breakpoint lies within a sequence of $45 \mathrm{bp}$ that is identical in both Alu sequences that had been sequenced (Figure 3).

\section{BRCA2 mutation analysis}

DNA sequencing performed by Myriad Genetic Laboratories on patient III: 22, who had lobular breast cancer, uncovered a BRCA2 exon $3542 \mathrm{G}>\mathrm{T}$ mutation, predicted to result in a truncated protein (L105X). Patient III: 25 was shown to carry the same mutation by DNA sequencing. Subsequently, SSCA analysis was used to test all available family members for the $542 \mathrm{G}>\mathrm{T}$ 
Table 2 Female breast cancer: pathological analysis and immunohistochemistry (IHC) results of selected markers in family MONI080

IHC

\begin{tabular}{|c|c|c|c|c|c|c|c|c|c|c|}
\hline Family ID & BRCA2/MSH2 & $\begin{array}{c}\text { Age at } \\
\text { diagnosis }\end{array}$ & Vital status & $\begin{array}{l}\text { Breast cancer } \\
\text { histopathology }\end{array}$ & ER & PR & CDH-I & MIB-I & p53 & HER2/ErbB-2 \\
\hline III: 5 & mut/wt & 42 & Alive & $\begin{array}{l}\text { LCIS with six foci of infiltrating } \\
\text { lobular carcinoma }\end{array}$ & +++ & +++ & - & + & ++ & - \\
\hline III: 18 & $\mathrm{mut} / \mathrm{wt}$ & 33 & Deceased & $\begin{array}{l}\text { Two foci }(1.6 \text { and } 1 \mathrm{~cm}) \text { of } \\
\text { infiltrating lobular carcinoma }\end{array}$ & +++ & + & +++ & + & ++ & - \\
\hline III: 22 & mut/wt & 34 & Deceased & Multicentric infiltrating lobular carcinoma & +++ & +++ & - & - & $+1-$ & - \\
\hline
\end{tabular}

Mut = heterozygous mutation; $\mathrm{Wt}=$ wild-type; $\mathrm{LCIS}=$ lobular carcinoma in situ; $\mathrm{DCIS}=$ ductal carcinoma in situ; $\mathrm{ER}=$ oestrogen receptor; $\mathrm{PR}=$ progesterone receptor; $\mathrm{CDH}$ $\mathrm{I}=\mathrm{E}$-cadherin.

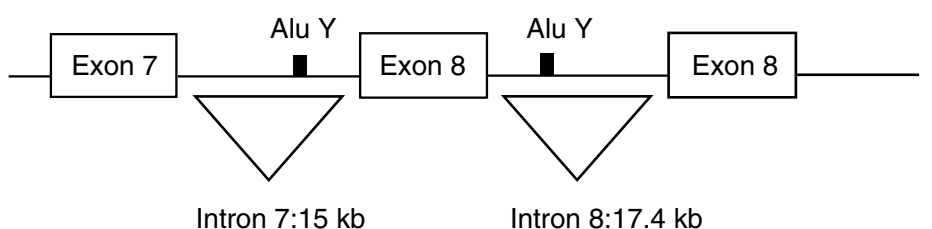

Deletion: $14.9 \mathrm{~kb}$

Figure 3 Characterisation of the MSH2 exon 8 deletion: the intron 7 Alu Y shares $83 \%$ identity with the intron 8 Alu Y. There are 17 Alu family sequences in intron 7 and 18 Alu family sequences in intron 8 . The MONI 080 deletion is the result of the possible recombination between identical 45 bp sequences found in both AluY sequences.

mutation. We confirmed that II: 20 , the father of III: 22 and III: 25 , is an obligate carrier of the BRCA2 exon $3542 \mathrm{G}>\mathrm{T}$ mutation and an obligate double heterozygote because his widow (II: 21 ), the mother of III: 22 and III: 25 , does not carry the BRCA2 mutation or the $\mathrm{MSH} 2$ mutation. Nine individuals were found to carry the L105X mutation: five of them are affected by BC and one was diagnosed with an ovarian papillary serous adenocarcinoma. Three mutation carriers are not affected, II: 1 (a 74 years-old male), III: 4 (a 53-year-old female) and III: 7 (a 42-year-old female) (Figure 1 and Table 1).

\section{Haplotype analysis}

Haplotype analysis using polymorphic markers spanning $\mathrm{MSH} 2$ and $B R C A 2$ was performed on 26 individuals. The $M S H 2$ linkage results were based on two markers, while the haplotype associated with the BRCA2 exon $3542 \mathrm{G}>\mathrm{T}$ mutation was assessed using five markers (Table 1). For both $M S H 2$ and $B R C A 2$, we identified a common haplotype shared by all mutation carriers, consistent with the inferred common ancestry. The five $\mathrm{MSH} 2$ exon 8 deletion carriers (III:10, III:15, II:18, III:19 and III:25, Table 1) shared an allele of identical size for two different $\mathrm{MSH} 2$ markers: TTTARepeat (intron 2) and TAAA-Repeat (intron 8) (alleles 170 and 288). All carriers of the cDNA deletion of the exon 8 are heterozygous for these two markers. A further four individuals were classified as obligate mutation carriers on the basis of reconstructed haplotypes and/or their position in the pedigree. We used somatic cell hybrids containing a maternally derived or a paternally derived chromosome 2 obtained from GMP Genetics (Waltham, MA, USA) from individual II: 18 to confirm the phase of the haplotype.

By direct genotyping, eight individuals in the MON1080 family (II: 2, III: 4, III: 5, III: 7, II: 16, III: 18, III: 22 , III: 25) were found to share a common allele for five different $B R C A 2$ markers $(3,4,1,3$, 
4). In seven of eight cases, we were able to rule out double heterozygosity for the exon 8 deletion. Patient III: 17 was only tested for three markers, but the result is consistent with the presence of a BRCA2 mutation and she was diagnosed with breast cancer at age 33 years. She is not a carrier of the $\mathrm{MSH} 2$ mutation. In contrast, her cousin, III: 25 , is a double heterozygote, and her father is an obligate double heterozygote (Table 1). Three other individuals are obligate mutation carriers.

\section{DISCUSSION}

We initially investigated the MON1080 family because of concern regarding $\mathrm{BC}$ risk, but examination of the pedigree showed that the incidence of CRC was just as high as that of BC (Figure 1). This family seemed an appropriate kindred in which to look for a novel breast-CRC predisposition gene. Linkage and molecular genetic analyses, however, revealed two independent mutations: a mutation in one MMR gene (MSH2) and in one BC susceptibility gene (BRCA2). There is no evidence that women in this pedigree were susceptible to $\mathrm{BC}$ solely because they carried an MMR gene mutation, or that CRC was associated with BRCA2 mutations, as has been previously suggested (Risch et al, 2001). Two individuals (II: 20 and his daughter III: 25) are double heterozygotes. The $B R C A 2$ exon $3542 \mathrm{G}>\mathrm{T}$ mutation was present in nine family members, among whom five women were diagnosed with $\mathrm{BC}$ and one was diagnosed with ovarian cancer. Three carriers are unaffected; two women had preventive mastectomies, and the third was a male, who recently died of a noncancer-related condition. In addition, eight $\mathrm{MSH} 2$ mutation carriers were identified in the MON1080 family. Mutation status was inferred for three individuals: two died of CRC and one died of an astrocytoma following a rectal cancer. Three additional individuals are affected by invasive cancer, while two remain unaffected by an HNPCC-related cancer. However, among the unaffected individuals, one has had two colon polyps removed that were not available for IHC or MSI testing and the other had both an anal squamous cell carcinoma and a keratoacanthoma that were MSS and did not show loss of MSH2 by IHC. The family history did not reveal additional cases of keratoacanthoma or other skin cancers. In patients with sebaceous gland adenocarcinoma (SGC) and a personal or family history of CRC, the diagnosis of MTS is clear. However, lack of a positive family history of SGC, absence of MSI and normal expression of $\mathrm{MSH} 2$ in tumours of patients indicate that the skin tumour can be considered a sporadic SGC (Entius et al, 2000). In this case, we suspect the keratoacanthoma is a sporadic occurrence and therefore a diagnosis of MTS is not sustained.

The histopathology of the breast tumours in the BRCA2 exon 3 $542 \mathrm{G}>\mathrm{T}$ mutation carriers is interesting (Table 2). Of the five female mutation carriers affected with breast cancer, one had a ductal carcinoma in situ, with foci of microinvasion, but the other four affected women had lobular invasive BC. Two of these four had areas of lobular carcinoma in situ as well. Our finding of four cases of lobular breast cancer in this family is consistent with results from our previous hospital-based series of breast cancers from Montreal, where we identified four BRCA2 mutation carriers among 127 women with first primary invasive BCs (Chappuis et al, 2001). Two of the four BRCA2 mutation carriers had lobular BC, and lobular BCs were statistically significantly overrepresented in $B R C A 2$ mutation carriers compared with noncarriers. Invasive lobular BC is seen in $4 \%$ of BRCA1-related breast cancer and $4 \%$ of sporadic controls, whereas $11 \%$ of $B R C A 2$-related breast cancer is of this subtype (Chappuis et al, 2000). Taken together, these findings suggest that lobular $\mathrm{BC}$ is more commonly a feature of germline BRCA2 mutation carriers than it is of BRCA1 mutation carriers, and its presence could be an indication to commence molecular studies of $B R C A 1 / 2$ with $B R C A 2$ analysis.
MSI-H and absence of MSH2 protein were observed in an astrocytoma removed from II: 11 (Figure 2). This patient is an obligate carrier of the $\mathrm{MSH} 2$ exon 8 deletion since his son carries this mutation. Leung et al previously reported the presence of a germline MMR gene mutation and MSI in patients with sporadic gliomas. They analysed four patients with microsatellite-unstable gliomas. Three had loss of $M S H 2$ protein by IHC and carried a germline $\mathrm{MSH} 2$ mutation. The fourth individual had a germline MLH1 mutation. Interestingly, only one of them reported a family history of CRC (Leung et al, 1998). Vasen et al (1996) suggested that the possible histological types of brain tumours that can occur in HNPCC kindreds include astrocytomas, oligodendrogliomas and rarely ependyomas. Other studies have reported germline MMR gene mutation in four patients with Turcot syndrome; three reported that a close relative had had CRC (Vasen et al, 1996; Miyaki et al, 1997; Hamilton et al, 2002).

Carriers of the MSH2 exon 8 deletion in this family share an identical disease haplotype (Table 1). The haplotype of the grandparents of the mutation carriers was determined by inference and confirmed the consistency of our haplotype analysis. The frequency of the haplotype of this $M S H 2$ mutation in the general population is not yet known, and it will be interesting to establish if other kindreds with exon 8 deletions have the same haplotype flanking $\mathrm{MSH} 2$ as reported here. Quantitative real-time PCR analysis confirmed that the germline intragenic deletion encompasses exon 8 and flanking intronic sequences. It is present in all patients showing a truncated protein by PTT for whom DNA was available for testing. Long-range PCR confirmed the exon 8 deletion, by revealing a $1.9 \mathrm{~kb}$ fragment containing the deletion breakpoint. The $14.9 \mathrm{~kb}$ deletion is the likely result of recombination between identical $45 \mathrm{bp}$ sequences found in both AluY sequences (Figure 3). Wang et al characterised several large genomic deletions in $M S H 2$ (exons 11-14; exons 12-15) and MLH1 (exon 4; exons 7-10) in patients suspected of HNPCC. They sequenced five deletion breakpoints where Alu-repetitive elements may be involved, but Alu-mediated recombination was not clearly demonstrated. Interestingly, they detected a deletion of exon 8 in the $\mathrm{MSH} 2$ gene in a patient by semiquantitative multiplex PCR, but because of the large intronic sequence they could not characterise the deletion breakpoint by long-rang PCR (Wang et al, 2003). By contrast, in the kindred reported here, following the observation of heterozygosity for intragenic $M S H 2$ markers TAAA-Rpt (Table 1) indicating that the deletion breakpoint would be localised downstream from this repetitive element, we were able to definitely characterise this mutation (Figure 3 ). It seems highly likely that other exon $8 \mathrm{cDNA}$ deletions reported in the literature are due to inter-Alu recombination as this region contains a large number of Alu-repetitive elements (17 Alu family sequences in intron 7; 19 Alu family sequences in intron 8 ), which could promote such deletions. The frequency of such large genomic deletion is probably underestimated; the PCR-based methods used in most molecular genetics laboratories do not allow their detection. In fact, Charbonnier et al (2002) estimated that large MMR gene rearrangements account for about $10 \%$ of the HNPCC cases in France. Wijnen et al (1998) reported similar findings in the Dutch population; $6.5 \%$ of the HNPCC cases are due to intragenic deletion in $M L H 1$ or $M S H 2$. Genomic rearrangements are an important component of the MMR mutation spectrum, and Alumediated recombination are likely responsible of a large amount of these intragenic deletions (Nystrom-Lahti et al, 1995; Viel et al, 2002).

In this large $\mathrm{BC} / \mathrm{CRC}$ kindred, we identified disease-associated mutations in both $B R C A 2$ and $M S H 2$. This is the first report of double heterozygotes with truncating mutations in predisposition genes for $\mathrm{BC}$ and CRC. The presence of the BRCA2 mutation explained the occurrence of breast and ovarian cancer in the kindred, and presence of the MSH2 mutation accounted for CRC, endometrial and brain cancer (astrocytoma). One individual with 
nonmedullary thyroid cancer (and breast cancer) carried a BRCA2 mutation. There were also two individuals with lung cancer, one of whom (II:7) is known to carry the BRCA2 mutation on the basis of the reconstructed haplotype and the presence of this mutation in his children. By reconstruction, he does not carry the $\mathrm{MSH} 2$ mutation. We could not establish the mutation status of the other male subject with lung cancer (II:9) at either locus (Figure 1 and Table 1).

Our results support the notion that early-onset BC in HNPCC may be due to mutations in other genes, such as $B R C A 2$, and that early-onset CRC in BRCA1/2 may be due to mutations in MMR genes, such as $M S H 2$. This report describes the phenotype of the first two individuals in whom truncating mutations in both genes have been identified. Clearly, it is not possible to draw firm conclusions from only two cases, but the double heterozygotes in this kindred do not appear to have an earlier age of onset than carriers of a single mutation, and the cancers appear to have independent genetic aetiologies. Moreover, based on the data presented here and other recent results (Muller et al, 2002), we do not consider that a single highly penetrant BC-CCR cancer susceptibility gene is likely to exist. Rather, in agreement with the most recent epidemiological reports, our findings argue that the two conditions (CRC and BC) are independent of each other (Newschaffer et al, 2001). Kindreds with the phenotype reported here are not frequently identified, but this detailed report demonstrates how a single family can contribute more generally to the understanding of the development of cancer in unusual situations such as double heterozygosity.

\section{ACKNOWLEDGEMENTS}

This manuscript is dedicated to the memory of SM. We thank all the family members who contributed to this work. Without their continued interest and support, we would not have been able to complete this study. All consented to have the family pedigree published. Moreover, we will supply each family member with a copy of this publication. We also thank Jennifer Ozaki, Nicola Matthews and Nora Wong for their important contributions to this study. This work was supported by grants to WDF from the Cancer Research Society Inc., the Judy Steinberg Trust and the Canadian Genetic Diseases Network. We also wish to acknowledge the involvement of all the clinicians and genetic counsellors in the ascertainment and management of this family; in particular, Jenna Scott, Tammy Stothers, Mary-Anne Young and Kelly Phillips. We thank Paolo Peterlongo PhD, (Memorial Sloan-Kettering Cancer Center, New York, NY, USA) for his help in the characterisation of the exon 8 deletion. None of the authors have any conflict of interest with respect to this manuscript.

\section{REFERENCES}

Aarnio M, Mecklin JP, Aaltonen LA, Nystromlahti M, Jarvinen HJ (1995) Life-time risk of different cancers in hereditary non-polyposis colorectal cancer (HNPCC) syndrome. Int J Cancer 64: 430-433

Boland CR, Thibodeau SN, Hamilton SR, Sidransky D, Eshleman JR, Burt W, Meltzer SJ, Rodriguez-Bigas MA, Fodde R, Ranzani GN, Srivastava S (1998) A National Cancer Institute Workshop on microsatellite instability for cancer detection and familial predisposition: development of international criteria for the determination of microsatellite instability in colorectal cancer. Cancer Res 58: 5248-5257

Borg A, Isola J, Chen J, Rubio C, Johansson U, Werelius B, Lindblom A (2000) Germline BRCA1 and HMLH1 mutations in a family with male and female breast carcinoma. Int J Cancer 85: 796-800

Caluseriu O, Cordisco EL, Viel A, Majore S, Nascimben R, Pucciarelli S, Genuardi M (2001) Four novel MSH2 and MLH1 frameshift mutations and occurrence of a breast cancer phenocopy in hereditary nonpolyposis colorectal cancer. Hum Mutat 17: 521

Chappuis PO, Hamel N, Paradis AJ, Deschenes J, Robidoux A, Potvin C, Cantin J, Tonin P, Ghadirian P, Foulkes WD (2001) Prevalence of founder BRCA1 and BRCA2 mutations in unselected French Canadian women with breast cancer. Clin Genet 59: 418-423

Chappuis PO, Nethercot V, Foulkes WD (2000) Clinico-pathological characteristics of BRCA1- and BRCA2-related breast cancer. Semin Surg Oncol 18: 287-295

Charbonnier F, Olschwang S, Wang Q, Boisson C, Martin C, Buisine MP, Puisieux A, Frebourg T (2002) MSH2 in contrast to MLH1 and MSH6 is frequently inactivated by exonic and promoter rearrangements in hereditary nonpolyposis colorectal cancer. Cancer Res 62(3): 848-853

Desai DC, Lockman JC, Chadwick RB, Gao X, Percesepe A, Evans DG, Miyaki M, Yuen ST, Radice P, Maher ER, Wright FA, de la Chapelle A (2000) Recurrent germline mutation in MSH2 arises frequently de novo. $J$ Med Genet 37: 646-652

Entius MM, Keller JJ, Drillenburg P, Kuypers KC, Giardello FM, Offerhaus GJ (2000) Microsatellite instability and expression of hMLH-1 and hMSH-2 in sebaceous gland carcinomas as markers for Muir-Torre syndrome. Clin Cancer Res 6: 1784-1789

Hamilton SR, Lui B, Parsons RE, Papadopoulos N, Jen J, Powell SM, Krush Aj, Berk T, Cohen Z (2002) The molecular basis of Turcot syndrome. $N$ Engl J Med 332: $839-847$

Honchel R, Halling KC, Schaid DJ, Pittelkow M, Thibodeau SN (1994) Microsatellite instability in Muir-Torre syndrome. Cancer Res 54: $1159-1163$
Kruse R, Lamberti C, Wang Y, Ruelfs C, Bruns A, Esche C, Lehmann P, Ruzicka T, Rutten A, Friedl W, Propping P (1996) Is the mismatch repair deficient type of Muir-Torre syndrome confined to mutations in the hMSH2 gene? Hum Genet 98: 747-750

Leung SY, Chan TL, Chung LP, Chan AS, Fan YW, Hung KN, Kwong WK (1998) Microsatellite instability and mutation of DNA mismatch repair genes in gliomas. Am J Pathol 153: $1181-1188$

Luce MC, Marra G, Chauhan DP, Laghi L, Carethers JM, Cherian SP, Hawn M, Binnie CG, Kam-Morgan LN, Cayouette MC (1995) In vitro transcription/translation assay for the screening of hMLH1 and hMSH2 mutations in familial colon cancer. Gastroenterol 109: $1368-1374$

Lynch HT, de la Chapelle A (1999) Genetic susceptibility to non-polyposis colorectal cancer. J Med Genet 36: $801-818$

Marcus VA, Madlensky L, Gryfe R, Kim H, So K, Millar A, Temple LK, Hsieh E, Hiruki T, Narod S, Bapat BV, Gallinger S, Redston M (1999) Immunohistochemistry for hMLH1 and hMSH2: a practical test for DNA mismatch repair-deficient tumors. Am J Surg Pathol 23: $1248-1255$

Miyaki M, Nishio J, Konishi M, Kikuchi-Yanoshita R, Tanaka K, Muraoka M, Nagato M, Chong JM (1997) Drastic genetic instability of tumors and normal tissues in Turcot syndrome. Oncogene 15: 2877-2881

Muller A, Edmonston TB, Corao DA, Rose DG, Pallazo JP, Becker H, Fry RD, Rueschoff J, Fishel R (2002) Exclusion of breast cancer as an integral tumor of hereditary nonpolyposis colorectal cancer. Cancer Res 62: $1014-1019$

Newschaffer CJ, Topham A, Herzberg T, Weiner S, Weinberg DS (2001) Risk of colorectal cancer after breast cancer. Lancet 357: 837-840

Nystrom-Lahti M, Kristo P, Nicolaides NC, Chang SY, Aaltonen LA, Moisio AL, Jarvinen HJ, Mecklin JP, Kinzler KW, Vogelstein B et al (1995) Founding mutations and Alu-mediated recombination in hereditary colon cancer. Nat Med 1(11): 1203-1206

Peltomaki P (2001) Deficient DNA mismatch repair: a common etiologic factor for colon cancer. Hum Mol Genet 10: 735-740

Risch HA, McLaughlin JR, Cole DEC, Rosen B, Bradley L, Kwan E, Jack E, Vesprini DJ, Kuperstein G, Abrahamson JLA, Fan I, Wong B, Narod SA (2001) Prevalence and penetrance of germline BRCA1 and BRCA2 mutations in a population series of 649 women with ovarian cancer. $A m J$ Hum Genet 68: $700-710$

Risinger JI, Barrett JC, Watson P, Lynch HT, Boyd J (1996) Molecular genetic evidence of the occurrence of breast cancer as an integral tumor 
in patients with the hereditary nonpolyposis colorectal carcinoma syndrome. Cancer 77: 1836-1843

Thompson DJ, Douglas F, Easton DF, Breast Cancer Linkage Consortium (2002) Cancer Incidence in BRCA1 mutation carriers. J Natl Cancer Inst 94: $1358-1365$

Vasen HF, Sanders EA, Taal BG, Nagengast FM, Griffioen G, Menko FH, Kleibeuker JH, Houwing-Duistermaat JJ, Meera Khan P (1996) The risk of brain tumours in hereditary non-polyposis colorectal cancer (HNPCC). Int J Cancer 65: 422-425

Vasen HF, Watson P, Mecklin JP, Lynch HT (1999) New clinical criteria for hereditary nonpolyposis colorectal cancer (HNPCC, Lynch syndrome) proposed by the International Collaborative group on HNPCC. Gastroenterology 116: $1453-1456$
Viel A, Petronzelli F, Della Puppa L, Lucci-Cordisco E, Fornasarig M, Pucciarelli S, Rovella V, Quaia M, Ponz de Leon M, Boiocchi M, Genuardi M (2002) Different molecular mechanisms underlie genomic deletions in the MLH1 Gene. Hum Mutat 20(5): $368-374$

Wang Y, Friedl W, Lamberti C, Jungck M, Mathiak M, Pagenstecher C, Propping P, Mangold E (2003) Hereditary nonpolyposis colorectal cancer: frequent occurrence of large genomic deletions in MSH2 and MLH1 genes. Int J Cancer 103(5): 636-641

Wijnen J, van der Klift $\mathrm{H}$, Vasen $\mathrm{H}$, Khan PM, Menko F, Tops C, Meijers Heijboer H, Lindhout D, Moller P, Fodde R (1998) MSH2 genomic deletions are a frequent cause of HNPCC. Nat Genet 20(4): $326-328$ 